AL IBTIDA: JURNAL PENDIDIKAN GURU MI (2017) VOL. 4(2): 247-256

DOI: http://dx.doi.org/10.24235/al.ibtida.snj.v4i2.1816

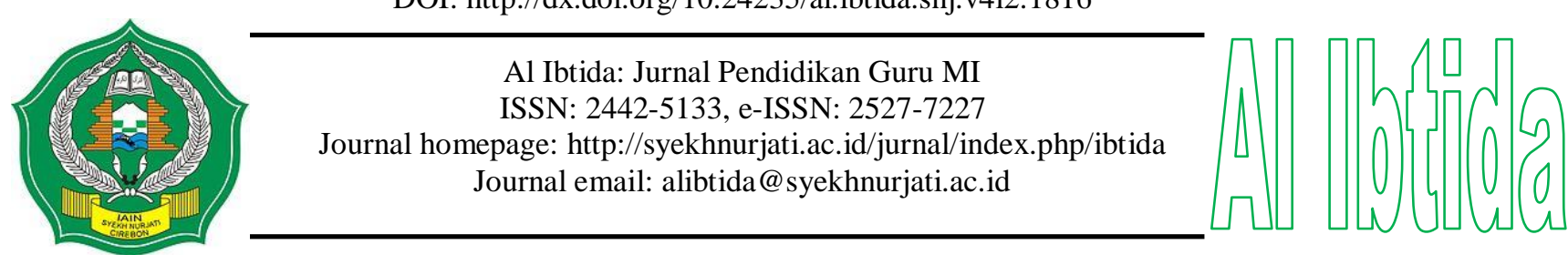

\title{
Pengukuran Pembelajaran Mandiri Berbasis Masalah pada Mahasiswa S1 PGSD UPBJJ UT Semarang: Confirmatory Factor Analysis
}

\author{
Ismartoyo* \\ *Program Studi Pendidikan Matematika, Fakultas Keguruan dan Ilmu Pendidikan, \\ Universitas Terbuka \\ Email: ismartoyo@ecampus.ut.ac.id \\ Nurmawati** \\ **Program Studi Pendidikan Matematika, Fakultas Keguruan dan Ilmu Pendidikan, \\ Universitas Terbuka \\ Email: nurmawati@ecampus.ut.ac.id \\ Abdul Karim*** \\ ***Program Studi Statistika, Fakultas Matematika dan Ilmu Pengetahuan Alam, \\ Universitas Muhammadiyah Semarang \\ Email: abdulkarim@unimus.ac.id
}

Received 12 August 2017; Received in revised form: 17 October 2017; Accepted 21 October 2017

Publish Online: 27 October 2017

\begin{abstract}
Abstrak
Belajar mandiri menjelaskan proses di mana setiap individu mengambil inisiatif, dengan atau tanpa bantuan orang lain, dalam mengidentifikasi kebutuhan belajar, merumuskan tujuan pembelajaran, mengidentifikasi manusia dan sumber daya materi untuk belajar, memilih dan menerapkan strategi pembelajaran yang tepat, dan mengevaluasi hasil belajar. Tujuan utama penelitian ini adalah mengetahui hubungan indikator-indikator yang membentuk masing-masing dimensi dari Belajar Mandiri melalui pembelajaran berbasis masalah pada mahasiswa S1 Program Studi Pendidikan Guru Sekolah Dasar (PGSD) Universitas Terbuka (UT) Kota Semarang semester 3 masa registrasi 2016/2017. Responden yang digunakan dalam penelitia ini sebanyak 79 mahasiswa. Data dianalisis secara deskriptif melalui reliabilitas (nilai Cronbach Alpha) untuk mengukur konsistensi variabel dan Confirmatory Factor Analysis (CFA) digunakan untuk menguji hubungan antara keterkaitan faktor yang membentuk variabel laten Belajar Mandiri. Hasilnya menunjukkan bahwa pengukuran Belajar Mandiri pada mahasiswa program studi S1 PGSD UPBJJ UT Semarang direpresentasikan oleh awareness, learning strategies, learning activities, evaluation, dan interpersonal skills. Hasil ini menyajikan bagaimana perspektif pembelajaran mandiri dalam kaitannya dengan pengalaman belajar mandiri. Artinya peserta didik diharapkan memiliki pengalaman dalam hal apa, bagaimana, dan mengapa mereka ingin belajar. Oleh karena itu, kajian kami dapat memberikan informasi dan motivasi serta preferensi sebagai pertimbangan dan pada akhirnya menghasilkan kualitas pembelajaran yang efektif.
\end{abstract}

Kata kunci: belajar mandiri, pembelajaran berbasis masalah, confirmatory factor analysis 


\begin{abstract}
Self-directed learning explains the process by which individuals take learning, with or without the help of others, in identifying learning needs, formulating learning objectives, identifying human and material resources for learning, selecting and applying appropriate learning strategies, and evaluating learning outcomes. The main purpose of this research is to know the correlation between the indicators that make up each dimension of Self Learning through the program based learning on the undergraduate students of PGSD Universitas Terbuka (UT) Semarang semester $3^{\text {rd }}$ of registration period 2016 / 2017. Data were analyzed descriptively for reliability (Cronbach Alpha values) and Factor Confirmation Analysis (CFA) is used to examine the relationship between the factors that make up Self-Directed. The results show that the Self-Directed measurement of undergraduate students of PGSD UPBJJ UT Semarang is represented by awareness, learning strategies, learning activities, evaluation, and interpersonal skills. This result presents how the independent learning perspective in relation to the self-learning experience.This means that learners are expected to have experience in what matters, how, and why they want to learn. Therefore, our study can provide effective and effective information and motivation and preferences.
\end{abstract}

Keywords: self-directed, problem based learning, confirmatory factor analysis

\title{
PENDAHULUAN
}

Belajar matematika di tingkat Perguruan Tinggi (PT) bukan sekedar mengingat pengetahuan faktual maupun penerapan sederhana, namun pada umumnya melibatkan kemampuan kognitif tingkat tinggi, seperti kemampuan remembering (mengingat), understanding (memahami), applying (menerapkan), analyzing (menganalisis), evaluating (mengevaluasi), dan creating (menciptakan). Mahasiswa yang belajar matematika khususnya di PT perlu mendapatkan tantangan berupa permasalahan menantang, guna menyiapkan mereka untuk menerapkan kemampuan matematikanya dalam bekerja setelah lulus nanti. Oleh karena itu, mahasiswa perlu diberikan kemampuan untuk menyelesaikan masalah.

Demikian pula yang terjadi dengan mahasiswa Universitas Terbuka (UT) program studi strata 1 Pendidikan Guru Sekolah Dasar (S1 PGSD), dengan memfokuskan pada mata kuliah yang berkaitan dengan materi ke SD-an. Mengingat materi yang harus dipelajari cukup banyak, sedangkan waktu pertemuan tutorial hanya 8 kali ditambah latar belakang pendidikan mahasiswa yang berbeda-beda, maka tutor diharapkan dapat memilih dan menerapkan strategi pembelajaran efektif yang dapat memotivasi mahasiswa dalam memahami materi mata kuliah Matematika ini. Penerapan strategi pembelajaran mandiri berbasis masalah dipandang dapat berperan efektif terhadap kemampuan mahasiswa dalam memecahkan masalah matematika yang dihadapi.

Belajar mandiri merupakan salah satu tujuan utama dan merupakan ciri utama yang diterapkan di jenjang pendidikan tinggi khususnya di UT. Belajar mandiri adalah dasar dari semua jenis pembelajaran (Slater \& Cusick, 2017). Semua individu mampu belajar mandiri tetapi tingkat perkembangan bervariasi karena perbedaan masing-masing, termasuk motivasi 
belajar, efektivitas diri, harga diri, kesadaran, keterbukaan terhadap pengalaman, bahkan kecerdasan. Belajar mandiri mengandung tiga dimensi: motivasi, metakognisi, dan selfregulation (Fox \& Riconscente, 2008).

Belajar mandiri dapat dipandang sebagai suatu proses dimana individu menetapkan tujuan, mencari sumber daya, memilih metode dan mengevaluasi kemajuan melalui refleksi kritis (Nkwake \& Morrow, 2016). Yang paling sering dikutip definisi belajar mandiri adalah definisi (Knowles, 1975) bahwa belajar mandiri menjelaskan proses di mana individu mengambil inisiatif, dengan atau tanpa bantuan orang lain, dalam mendiagnosis kebutuhan belajar mereka, merumuskan tujuan pembelajaran, mengidentifikasi manusia dan sumber daya materi untuk belajar, memilih dan menerapkan strategi pembelajaran yang tepat, dan mengevaluasi hasil belajar.

Belajar mandiri dapat dilihat sebagai suatu proses atau sebagai aspek psikologis, terutama sebagai atribut kepribadian. Dari perspektif ini, mahasiswa yang belajar secara mandiri adalah seorang individu dengan tingkat efisiensi tinggi, intrinsik termotivasi, seorang individu yang menetapkan tujuan dan memilih strategi yang tepat untuk mencapai tujuan tersebut, dan yang bersedia untuk memenuhi tantangan baru (Pilling-Cormick \& Garrison, 2013) (Cazan \& Schiopca, 2014).

Belajar mandiri cenderung dikaitkan dengan prestasi akademik, dan dengan ciri-ciri kepribadian (Kirwan, Lounsbury, \& Gibson, 2014). Para peneliti juga mencatat bahwa peserta didik yang mandiri memiliki tingkat efisiensi serta ciri kepribadiannya menjelaskan isi pembelajaran mandiri (Cazan \& Schiopca, 2014) (Payne, Rocks, \& Schaffner, 2014). James (2016) juga menyatakan bahwa proses perkembangan mempengaruhi belajar mandiri terkait dengan ciri-ciri kepribadian.

Penelitian ini mengkaji pembelajaran mandiri berbasis masalah sebagai ciri kepribadian bukan sebagai suatu proses. Kirwan et al., (2014) menekankan bahwa ciri-ciri kepribadian dapat mempengaruhi atau memberikan landasan bagi mahasiswa yang belajar secara mandiri, serta proses pembentukan Big Five model kepribadian merupakan "pengorganisasian skema" untuk memahami belajar mandiri berhubunganan dengan kepribadian.

Tujuan penelitian ini adalah untuk mengetahui hubungan indikator-indikator yang membentuk masing-masing dimensi dari belajar mandiri dengan berbasis masalah pada mahasiswa program studi S1 PGSD UT Kota Semarang semester 3 masa registrasi 2016/2017. Penelitian sebelumnya oleh Chou \& Chen (2008) menunjukkan bahwa belajar mandiri dan prestasi akademik ada keterkaitan studi melaporkan terdapat korelasi positif antara belajar mandiri dan IPK dan antara belajar mandiri dan tingkat kelas. Mereka juga melaporkan bahwa pembelajaran mandiri memprediksi keberhasilan akademis mahasiswa. 


\section{METODE PENELITIAN}

Data yang digunakan dalam penelitian ini adalah data primer. Pada penelitian ini yang dijadikan unit observasi adalah seluruh mahasiswa program studi S1 PGSD UPBJJ UT Semarang masa registrasi 2016/2017.2 yang mengambil mata kuliah Pembelajaran Matematika SD. Adapun data yang digunakan adalah persepsi mahasiswa tentang pembelajaran mandiri berbasis masalah.

Variabel dalam penelitian ini terdiri dari satu variabel laten, lima dimensi dan dua belas indikator untuk masing-masing dimensi. variabel laten dalam penelitian ini adalah pembelajaran mandiri berbasis masalah, variabel ini tidak dapat diukur secara langsung, dimana variabel ini diukur berdasarkan Williamson (2007), dimana belajar mandiri berbasis masalah terdiri dari beberapa dimensi, diantaranya : awareness, learning strategies, learning activity, evaluation, dan interpersonal skills.

Selanjutnya, tahapan analisis yang dilakukan dalam penelitian ini didasarkan pada tujuan dari penelitian. Analisis yang dilakukan sebagai berikut (Zhoc \& Chen, 2016):

a. Pengujian uni dimensionalitas setiap dimensi dengan menggunakan Confirmatory Factor Analysis (CFA) melalui tahapan pengembangan struktur berbasis konsep dan teori, serta mengkonstruksi diagram Path. CFA dilakukan berdasarkan faktor hipotesis yang digunakan, selanjutnya untuk memperkuat hipotesis yang dibangun, validitas konstruk dilakukan. Mengkonstruk validitas melibatkan validitas konvergen dan validitas diskriminan, validitas konvergen dievaluasi berdasarkan masing-masing koefisien loading factor yang signifikan dan reliabilitas komposit dari variabel laten

b. Interpretasi hasil yang sudah memenuhi kriteria.

\section{HASIL DAN PEMBAHASAN}

\section{A. Reliabilitas Instrumen}

Reliabilitas item untuk masing-masing indikator belajar mandiri dalam nilai Cronbach Alpha yang mengukur konsistensi variabel ditunjukkan pada Tabel 1. Menurut de Vet, Mokkink, Mosmuller, \& Terwee (2017), nilai Cronbach Alpha diklasifikasikan berdasarkan indeks reliabilitas 0,90- 1.00 sangat tinggi, 0,70-0,89 tinggi, 0,30-0,69 moderat, dan 0,00 sampai 0,30 rendah. Hasil penelitian menunjukkan bahwa Alpha Cronbach untuk masing-masing indikator pada klasifikasi tinggi, lebih tinggi dari 0,70. 
Tabel 1. Nilai Cronbach Alpha untuk Masing-masing Indikator

\begin{tabular}{lcc}
\hline Variabel Laten & Jumlah Item & Cronbach Alpha \\
\hline Awareness & 12 & 0,7 \\
Learning strategies & 12 & 0,84 \\
Learning activities & 12 & 0,71 \\
Evaluation & 12 & 0,74 \\
Interpersonal Skills & 12 & 0,74 \\
\hline
\end{tabular}

\section{B. Confirmatory Factor Analysis (CFA)}

Selanjutnya, analisis faktor konfirmasi (CFA) dilakukan untuk menguji hubungan mendasar antara seperangkat indikator terhadap dimensi. Estimasi maksimum likelihood digunakan untuk menghasilkan model pengukuran yang diestimasi, estimasi maksimum likelihood dipilih karena merupakan metode estimasi yang kuat yang mampu menangani sampel dan distribusi besar yang berangkat dari normalitas (Wood, 2017). Model pengukuran terdiri dari indikator untuk masing-masing konstruk, semua konstruksi variabel laten berkorelasi satu sama lain. Model fit dievaluasi menggunakan indeks kecocokan. Estimasi parameter individu diuji dengan menggunakan rasio kritis (Adachi, 2016).

Penilaian model fit didasarkan pada beberapa kriteria termasuk ketidaksesuaian absolut dan indeks kecocokan relatif. Indeks ketidaksesuaian absolut meliputi roor mean square error approximation (RMSEA;Hair, Black, Babin, Anderson, \& Tatham, 2006) dan indeks kebaikan relatif yang digunakan dalam penelitian ini adalah indeks kecocokan komparatif, Tucker Lewis Index dan incremental fit index ( CFI, TLI, IFI;Hair et al., 2006). Hair Jr, Hult, Ringle, \& Sarstedt (2016) menyatakan bahwa model sesuai ketika (i) nilai CMIN / df adalah antara 1 dan 5, yang dapat diterima atau dapat diterima sesuai antara model dan data, dan (ii) semakin kecil indeks RMSEA mengindikasikan error dapat diterima.

Pengujian secara keseluruhan untuk model menunjukkan bahwa sesuai dan dapat diterima berdasarkan indikator yang disarankan olehHair et al., (2006). Nilai CMIN / df = 1.667, dan RMSEA = 0,099, menunjukkan bahwa data dari sampel sesuai dengan model. Gambar 1 menunjukkan model pengukuran untuk Belajar Mandiri. 


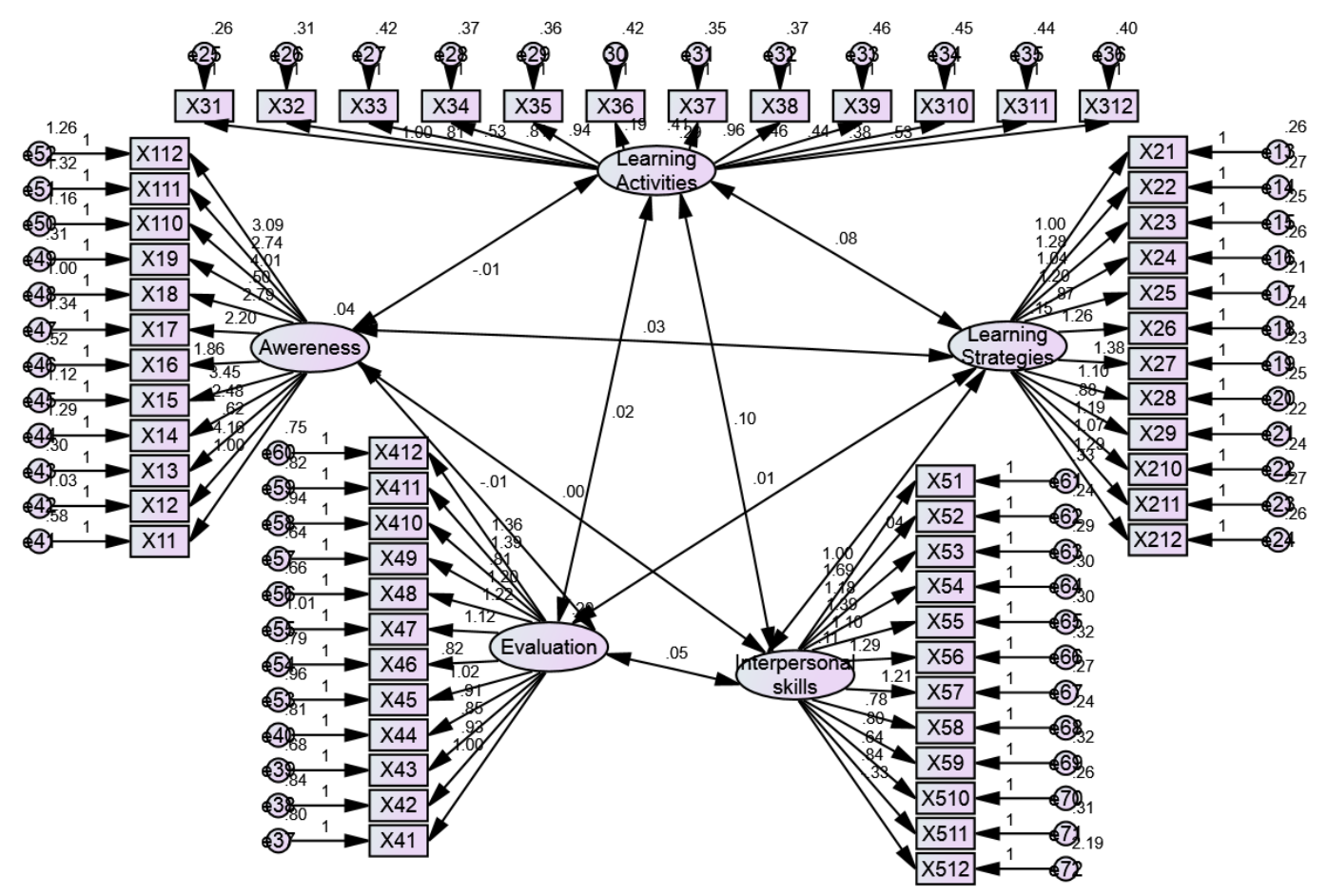

Gambar 1. Diagram Path

Masing-masing variabel laten diukur dengan menggunakan dua belas veriabel indikator. Untuk model pengukuran, signifikansi dari penduga-penduga parameter merupakan indikasi dari validitas variabel manifes terhadap variabel laten yang diukur. Maka diperlukan tahapan untuk menguji signifikansi dengan hipotesis sebagai berikut (Jalali-Farahani et al., 2017) :

$\mathrm{H}_{0}: \lambda_{\mathrm{i}}=0$ (loading factor tidak signifikan dalam mengukur variabel laten)

$\mathrm{H}_{1}: \lambda_{\mathrm{i}} \neq 0$ (loading factor signifikan dalam mengukur variabel laten)

Berikut nilai faktor loading dan pengujian signifikasi masing-masing indikator terhadap variabel laten yang disajikan pada tabel 2 berikut:

Tabel 2. Nilai Faktor Loading untuk Masing-masing Indikator

\begin{tabular}{|c|c|c|c|c|}
\hline \multicolumn{3}{|c|}{ Hubungan } & Estimate & P-value \\
\hline X11 & $<---$ & Awereness & 1.000 & \\
\hline X12 & $<---$ & Awereness & 4.156 & $0.062 * *$ \\
\hline X13 & $<---$ & Awereness & .616 & 0.198 \\
\hline X14 & $<---$ & Awereness & 2.485 & $0.092 * *$ \\
\hline X15 & $<---$ & Awereness & 3.447 & $0.068 * *$ \\
\hline X16 & $<---$ & Awereness & 1.856 & $0.080 * *$ \\
\hline X17 & $<--$ & Awereness & 2.202 & 0.105 \\
\hline X18 & $<--$ & Awereness & 2.795 & $0.075^{* *}$ \\
\hline X19 & $<---$ & Awereness & .504 & 0.261 \\
\hline
\end{tabular}




\begin{tabular}{|c|c|c|c|c|}
\hline \multicolumn{3}{|c|}{ Hubungan } & Estimate & P-value \\
\hline $\mathrm{X} 110$ & $<--$ & Awereness & 4.007 & $0.064 * *$ \\
\hline $\mathrm{X} 111$ & $<--$ & Awereness & 2.740 & $0.085^{* *}$ \\
\hline $\mathrm{X} 112$ & $<---$ & Awereness & 3.094 & $0.076^{* *}$ \\
\hline $\mathrm{X} 21$ & $<---$ & Learning_Strategies & 1.000 & \\
\hline $\mathrm{X} 22$ & $<---$ & Learning_Strategies & 1.281 & $0.000 *$ \\
\hline $\mathrm{X} 23$ & $<---$ & Learning_Strategies & 1.043 & $0.000 *$ \\
\hline $\mathrm{X} 24$ & $<---$ & Learning_Strategies & 1.205 & $0.000 *$ \\
\hline $\mathrm{X} 25$ & $<---$ & Learning_Strategies & .871 & $0.000 *$ \\
\hline $\mathrm{X} 26$ & $<---$ & Learning_Strategies & 1.261 & $0.000 *$ \\
\hline $\mathrm{X} 27$ & $<---$ & Learning_Strategies & 1.381 & $0.000 *$ \\
\hline $\mathrm{X} 28$ & $<---$ & Learning_Strategies & 1.103 & $0.000 *$ \\
\hline X29 & $<---$ & Learning_Strategies & .881 & $0.000 *$ \\
\hline $\mathrm{X} 210$ & $<---$ & Learning_Strategies & 1.188 & $0.000 *$ \\
\hline X211 & $<---$ & Learning_Strategies & 1.068 & $0.000 *$ \\
\hline $\mathrm{X} 212$ & $<---$ & Learning_Strategies & 1.289 & $0.000 *$ \\
\hline X31 & $<---$ & Learning_Activities & 1.000 & \\
\hline X32 & $<---$ & Learning_Act & .807 & $0.000 *$ \\
\hline X33 & $<---$ & Learning_Activities & .531 & $0.003 *$ \\
\hline X34 & $<---$ & Learning_Activities & .811 & $0.000 *$ \\
\hline $\mathrm{X} 35$ & $<---$ & Learning_Activities & .939 & $0.000 *$ \\
\hline X36 & $<---$ & Learning_Activ & .193 & 0.237 \\
\hline X37 & $<---$ & Learning_Activities & .407 & $0.009 *$ \\
\hline X38 & $<---$ & Learning_Activities & .965 & $0.000 *$ \\
\hline X39 & $<---$ & Learning_Activities & .465 & $0.009 *$ \\
\hline X310 & $<---$ & ig_Activ & .439 & \\
\hline X311 & $<---$ & Learning_Activities & .375 & $0.029 *$ \\
\hline X312 & $<--$ & Learning_Activities & .528 & $0.002 *$ \\
\hline $\mathrm{X} 41$ & $<---$ & Evalu & 1.000 & \\
\hline $\mathrm{X} 42$ & $<---$ & Evalu & .930 & $0.016^{*}$ \\
\hline $\mathrm{X} 43$ & $<---$ & Evaluation & .854 & $0.015^{*}$ \\
\hline X44 & $<---$ & Evalu & .908 & $0.016^{*}$ \\
\hline $\mathrm{X} 45$ & $<---$ & Evalu & 1.016 & $0.015^{*}$ \\
\hline $\mathrm{X} 46$ & $<---$ & Evalu & .821 & $0.022 *$ \\
\hline $\mathrm{X} 47$ & $<---$ & Evalu & 1.119 & $0.012 *$ \\
\hline $\mathrm{X} 48$ & $<---$ & Evaluation & 1.225 & $0.004 *$ \\
\hline X49 & $<---$ & Evalu & 1.197 & $0.004 *$ \\
\hline $\mathrm{X} 410$ & $<---$ & Evaluation & .812 & $0.031 *$ \\
\hline X411 & $<---$ & Evaluation & 1.389 & $0.004 *$ \\
\hline $\mathrm{X} 412$ & $<---$ & Evaluation & 1.361 & $0.004 *$ \\
\hline X51 & $<---$ & Interpersonal_skills & 1.000 & \\
\hline X52 & $<---$ & Interpersonal_skills & 1.694 & $0.000 *$ \\
\hline X53 & $<---$ & Interpersonal_skills & 1.178 & $0.000 *$ \\
\hline X54 & $<---$ & Interpersonal_skills & 1.386 & $0.000 *$ \\
\hline X55 & $<---$ & Interpersonal_skills & 1.099 & $0.000 *$ \\
\hline X56 & $<---$ & Interpersonal_skills & 1.294 & $0.000 *$ \\
\hline X57 & $<---$ & Interpersonal_skills & 1.206 & $0.000 *$ \\
\hline
\end{tabular}




\begin{tabular}{rlrr}
\hline Hubungan & Estimate & P-value \\
\hline X58 <--- & Interpersonal_skills & .778 & $0.003^{*}$ \\
X59 <--- & Interpersonal_skills & .795 & $0.005^{*}$ \\
X510 <--- & Interpersonal_skills & .637 & $0.009 *$ \\
X511 <--- & Interpersonal_skills & .838 & $0.004^{*}$ \\
X512 <--- & Interpersonal_skills & -.331 & 0.568 \\
\hline Ket $:$ & signifikan pada alfa 5 persen; $* *$ signifikan pada alfa 10 persen
\end{tabular}

Berdasarkan tabel 2 di atas diperoleh bahwa variabel laten awareness secara signifikan dibentuk oleh indikator X12, X14, X15, X16, X18, X110, X111, X112. Variabel laten Learning Strategies dan Evaluation secara signifikan dibentuk oleh semua indikatornya, sedangkan variabel Learning Activities hanya indikator X36 yang tidak signifikan selebihnya membentuk hubungan. Selanjutnya, sebagian besar indikator Interpersonal Skills signifikan hanya satu yang tidak siginifikan yakni indikator X512.

Hasil dari penelitian ini mengindikasikan bahwa pengukuran Belajar Mandiri pada mahasiswa program studi S1 PGSD UPBJJ UT Semarang direpresentasikan oleh lima faktor, hasil ini menyajikan bagaimana perspektif pembelajaran mandiri dalam kaitannya dengan pengalaman belajar, seperti peserta didik memiliki pengalaman dalam hal apa, bagaimana, dan mengapa mereka ingin belajar. Hasil ini sesuai dengan penelitian Cadorin, Bortoluzzi, \& Palese (2013) dimana motivation, learning strategies, learning activities, interpersonal skills merepresentasikan pengukuran variabel Belajar Mandiri. Oleh karena itu, kajian kami dapat memberikan informasi dan motivasi serta preferensi sebagai pertimbangan dan pada akhirnya menghasilkan kualitas pembelajaran yang efektif.

\section{SIMPULAN}

Berdasarkan uraian di atas, dapat disimpulkan bahwa pengukuran Belajar Mandiri pada mahasiswa program studi S1 PGSD UPBJJ UT Semarang direpresentasikan oleh awareness, learning strategies, learning activities, evaluation, dan interpersonal skills. Hasil ini menyajikan bagaimana perspektif pembelajaran mandiri dalam kaitannya dengan pengalaman belajar mandiri. Selanjutnya, pembelajaran mandiri bisa menjadi alat yang berguna dalam mendiagnosis kebutuhan belajar siswa dalam rangka meningkatkan penyesuaian akademik mereka. Selain itu, melalui belajar mandiri pendidik dan peserta didik diharapkan memiliki pemahaman yang jelas tentang konsep dan sifat kemampuan belajar mandiri untuk pengembangan lebih lanjut. 


\section{DAFTAR PUSTAKA}

Adachi, K. (2016). Confirmatory Factor Analysis. In Matrix-Based Introduction to Multivariate Data Analysis (pp. 145-159). Singapore: Springer Singapore. http://doi.org/10.1007/978981-10-2341-5_10

Cadorin, L., Bortoluzzi, G., \& Palese, A. (2013). Nurse Education Today The Self-Rating Scale of Self-Directed Learning ( SRSSDL ): A factor analysis of the Italian version. YNEDT, 33(12), 1511-1516. http://doi.org/10.1016/j.nedt.2013.04.010

Cazan, A.-M., \& Schiopca, B.-A. (2014). Self-directed learning, personality traits and academic achievement. Procedia-Social and Behavioral Sciences, 127, 640-644.

Chou, P.-N., \& Chen, W.-F. (2008). Exploratory study of the relationship between self-directed learning and academic performance in a web-based learning environment. Online Journal of Distance Learning Administration, 11(1), 15-26.

de Vet, H. C. W., Mokkink, L. B., Mosmuller, D. G., \& Terwee, C. B. (2017). Spearman-Brown prophecy formula and Cronbach's alpha: different faces of reliability and opportunities for new applications. Journal of Clinical Epidemiology, 85, 45-49. http://doi.org/10.1016/j.jclinepi.2017.01.013

Fox, E., \& Riconscente, M. (2008). Metacognition and self-regulation in James, Piaget, and Vygotsky. Educational Psychology Review, 20(4), 373-389.

Hair, J. F., Black, W. C., Babin, B. J., Anderson, R. E., \& Tatham, R. L. (2006). Multivariate data analysis (Vol. 6): Pearson Prentice Hall Upper Saddle River. NJ. 連結.

Hair Jr, J. F., Hult, G. T. M., Ringle, C., \& Sarstedt, M. (2016). A primer on partial least squares structural equation modeling (PLS-SEM). Sage Publications.

Jalali-Farahani, S., Amiri, P., Karimi, M., Gharibzadeh, S., Mirmiran, P., \& Azizi, F. (2017). Socio-Behavioral Factors Associated with Overweight and Central Obesity in Tehranian Adults: a Structural Equation Model. International Journal of Behavioral Medicine, 24(1), 110-119. http://doi.org/10.1007/s12529-016-9574-7

James, F. (2016). The "third age"perspective: enrichment and informal modes of learning in an outdoor sketching group for older adults. International Journal of Lifelong Education, 116.

Kirwan, J. R., Lounsbury, J. W., \& Gibson, L. W. (2014). An Investigation of the Big Five and Narrow Personality Traits in Relation to Self-Regulated Learning. Journal of Psychology and Behavioral Science, 2(1), 1-11.

Knowles, M. S. (1975). Self-directed learning.New York: Associated Press.

Nkwake, A. M., \& Morrow, N. (2016). Clarifying concepts and categories of assumptions for use in evaluation. Evaluation and Program Planning, 59, 97-101.

Payne, S. S., Rocks, J., \& Schaffner, B. (2014). Self-direction in learning and academic motivation development in undergraduate health profession students. International Journal 
of Self-Directed Learning, 11(1), 41-51.

Pilling-Cormick, J., \& Garrison, D. R. (2013). Self-directed and self-regulated learning: Conceptual links. Canadian Journal of University Continuing Education, 33(2).

Slater, C. E., \& Cusick, A. (2017). Factors related to self-directed learning readiness of students in health professional programs: A scoping review. Nurse Education Today, 52, 28-33. http://doi.org/10.1016/j.nedt.2017.02.011

Williamson, S. N. (2007). Development of a self-rating scale of self-directed learning. Nurse Researcher, 14(2), 66-83.

Wood, S. N. (2017). Generalized additive models: an introduction with R. CRC press.

Zhoc, K. C. H., \& Chen, G. (2016). Reliability and validity evidence for the Self-Directed Learning Scale (SDLS). Learning and Individual Differences, 49, 245-250. http://doi.org/10.1016/j.lindif.2016.06.013 